\title{
Sebaran Karbon Organik Total dalam Sedimen Dasar di Muara Sungai Jajar, Kabupaten Demak
}

\author{
Tulus Aldrian Siregar ${ }^{1}$, Alfi Satriadi ${ }^{1}$, Wasito Atmodjo ${ }^{1}$, Muslim${ }^{1}$, Gentur Handoyo ${ }^{1}$ \\ Departemen Oseanografi, Fakultas Perikanan dan Ilmu Kelautan, Universitas Diponegoro \\ Jl. Prof. H. Soedarto, S.H, Tembalang Semarang. 50275 Telp/fax (024)7474698 \\ Email : tulus.siregarneber@gmail.com
}

\begin{abstract}
Abstrak
Muara Sungai Jajar terletak di bagian utara Kabupaten Demak. Sungai Jajar mengangkut materi dari berbagai kegiatan antropogenikdari area permukiman penduduk, pertambakan, dan hutan mangrove. Hal ini akan berdampak pada penurunan kesuburan dan kualitas perairan di daerah muara apabila tidak ada kegiatan monitoring atau pengawasan. Karbon organik merupakan salah satu indikator yang dapat digunakan untuk mengetahui kesuburan lingkungan laut. Penelitian ini bertujuan untuk mengetahui sebaran karbon organik total (KOT) pada sedimen dasar di muara Sungai Jajar, Demak. Penelitian dilakukan dari tanggal 19 Agustus 2020 sampai dengan 15 Oktober 2020. Analisis karbon organik total dilakukan dengan metode AOAC (Association of Official Agriculture Chemist) dan $\mathrm{pH}$ pada sedimen, analisis ukuran butir sedimen dengan metode pengayakan dan pemipetan, analisis kualitas perairan, dan analisis arah dan kecepatan arus laut dengan pendekatan model hidrodinamika. Hasil penelitian menunjukkan, bahwa sedimen di Muara Sungai Jajar berfraksi lanau, lanau pasiran, dan pasir lanauan. Sebaran KOT dari Muara Sungai Jajar menyebar ke arah laut terbuka. Kosentrasi KOT pada daerah Muara Sungai Jajar berada pada kisaran 6,20-8,88\%. Karbon organik diangkut oleh arus yang relatif kecil dengan kecepatan $0,002-0,045 \mathrm{~m} / \mathrm{s}$ menuju barat daya - selatan dan tenggelam pada perairan yang lebih dalam, sehingga semakin dalam perairan makan kosentrasi KOT akan semakin besar.
\end{abstract}

Kata kunci: karbon organik total, ukuran butir, sedimen dasar, Muara Sungai Jajar.

\begin{abstract}
Abstact
Jajar River estuary is located in the north of the administrative area of Demak Regency. Jajar River transports material from various anthropogenic activities, such as human settlements, aquaculture, mangrove forests. The decline in water quality is caused by the concentration of organic matter, a decrease in dissolved oxygen content, and the influence of other water quality parameters. One of the important materials for organic matter is the element $C$ (carbon). Organic carbon is one indicator of the fertility of the marine environment. The study was conducted to determine the distribution of total organic carbon (TOC) in the bottom sediments at the mouth of the Jajar River, Demak. The research was carried out on 19 August 2020 to 15 October 2020. Analysis of total organic carbon was carried out using the AOAC (Association of Official Agriculture Chemist) method and pH of the sediment, grain size analysis of sediment with sieving and pipetting methods, water quality analysis, and directional analysis. and the velocity of ocean currents using Mike 21 software. The results show that the sediment in the study has silt, sandy silt and silt sand. The distribution of TOC in the bottom sediment at the Jajar River Estuary spreads towards the open sea. The concentration of TOC in the Jajar River Estuary was $6.20-8.88 \%$. Organic carbon transported by relatively small currents with a speed of $0.002-0.045 \mathrm{~m} / \mathrm{s}$ to the southwest - south will sink in deep waters, so that the deeper the waters, the greater the KOT concentration. Water quality factors that affect the KOT concentration are currents, tides and brightness.
\end{abstract}

Keywords: Total Organic Carbon, Sediment grain size, Jajar River Estuary

\section{PENDAHULUAN}

Muara Sungai Jajar terletak di bagian utara Kabupaten Demak. Sungai Jajar merupakan jalur transportasi bagi perahu nelayan menuju muara, disamping itu memiliki peran mengangkut materi dari berbagai kegiatan antropogenik di sekitar muara seperti permukiman penduduk, pertambakan, dan 
hutan mangrovePenurunan kualitas perairan dapat dilihat dari kosentrasi bahan organik, penurunan kandungan oksigen terlarut, serta pengaruh parameter kualitas perairan lainnya. Salah satu materi pembentuk bahan organik yang penting adalah unsur C (karbon). Kandungan karbon organik dalam sedimen menunjukkan kandungan bahan organik yang dapat mengindikasikan kuantitas nutrien didalamnya. Karbon organik merupakan salah satu indikator kesuburan lingkungan laut. Bila kandungannya melebihi ambang batas, karbon organik dapat menurunkan kualitas perairan (Nagur, 2017).

Peningkatan karbon organik harus dikendalikan karena apabila jumlahnya melebihi ambang batas maka akan terjadi pencemaran. Karbon organik dalam perairan yang bebas disimpan dalam bentuk lepasan. akan jatuh ke dasar kemudian diadsorpsi oleh sedimen dasar. Ukuran butir sedimen akan memengaruhi ikatan unsur yang terdapat di dalamnya. Adsorpsi dipengaruhi oleh luas permukaan yang mengalami kontak. Semakin luas permukaan adsorben, semakin tinggi pula zat yang teradsorpsi. Luas permukaan adsorben ditentukan oleh ukuran partikel dan jumlah dari adsorben (Syauqiah et al., 2011).

Penelitian tentang kesuburan perairan di Muara Sungai Jajar, Demak pernah dilakukan oleh Wijayanto et al., (2015) yaitu mengkaji kesuburan perairan berdasarkan kandungan nitrat dan fosfat. Kesuburan berdasarkan kandungan nitrat tergolong dalam kesuburan rendah (oligotrofik) hingga sedang (mesotrofik), sedangkan kandungan fosfatnya tergolong dalam kategori subur (eutrofik). Penelitian lainnya yang pernah dilakukan adalah sebaran ukur butiran sedimen. Sihombing et al. (2021) menjelaskan bahwa di muara Sungai Jajar ditemukan tiga jenis sedimen yaitu pasir lanauan, lanau pasiran, dan lanau. Penelitian tentang karbon organik dalam sedimen dan distribusinya belum pernah dilakukan. Diharapakan penelitian ini dapat dijadikan sebagai informasi awal tingkat kesuburan perairan.

\section{MATERI DAN METODE}

Pengambilan data lapangan meliputi sedimen, kualitas perairan, dan arus pada tanggal 19 Agustus 2020. Data sekunder meliputi data ukuran butir sedimen, kualitas perairan, data arus permukaan, data BATNAS ( Batimetri Nasional) BIG tahun 2020, data pasang surut Kota Semarang BIG bulan Agustus 2020, dan peta Rupa Bumi Indonesia BIG skala 1: 25.000 Tahun 2019. Pengambilan sampel dilakukan dengan menggunakan sediment grab di 11 stasiun (Gambar 1), kemudian sampel dimasukkan ke dalam plastik dan diberi tanda/label. Sampel yang sudah di beri label kemudian dimasukkan kedalam coolbox dan dibawa ke laboratorium untuk di analisis.

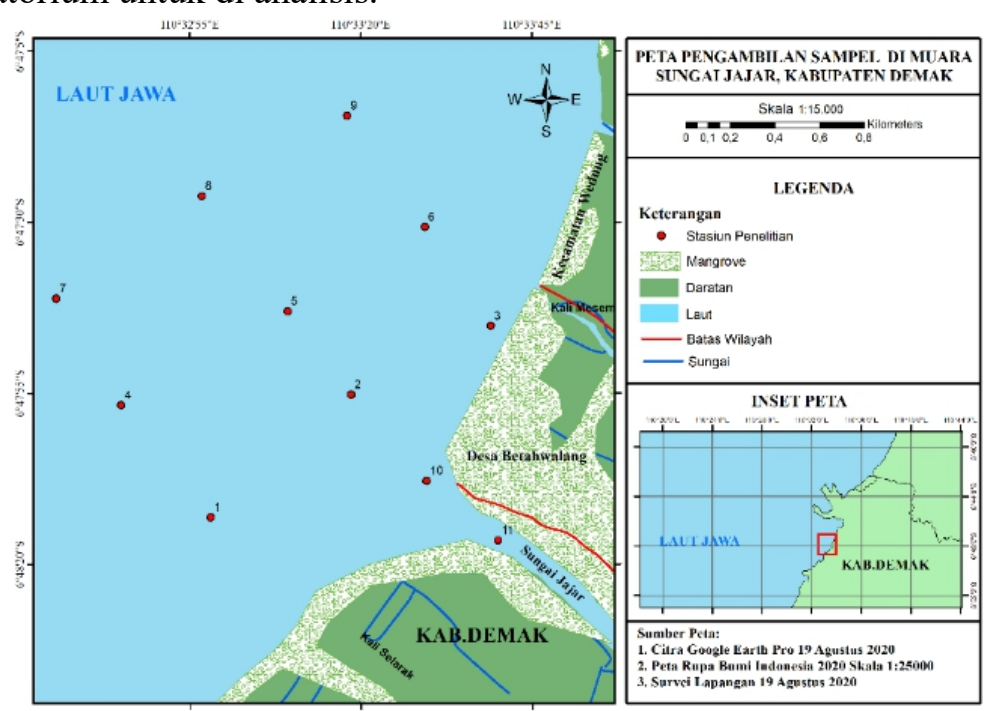

Gambar 1. Peta Lokasi Penelitian

\section{Kualitas Perairan}


Pengukuran kualitas perairan dan arus laut dilakukan secara insitu. Sampel air digunakan untuk mengetahui karakteristik perairan. Pengukuran DO dan suhu diukur dengan memasukan sensor water quality checker pada air yang telah diambil dengan botol nansen pada kedalaman air 0,8d perairan. Sampel air tersebut diukur juga nilai salinitas dengan refractometer dengan memasukkan sampel air ke dalam sensor bias. Kecerahan diukur dengan menggunakan piringan secchi disk ke dalam perairan laut. Secchi disk dimasukan ke dalam perairan kemudian dilihat skala dimana Secchi disk masih terlihat jelas (K1) dan skala dimana Secchi disk terlihat remang-remang (K2). Menurut Effendi (2003), persamaan untuk mengukur kecerahan sebagai berikut:

$$
D=\frac{(K 1+K 2)}{2}
$$

Pengukuran arus laut dengan metode Eulerian pada satu titik secara insitu di permukaan laut dengan menggunakan current meter.

\section{Kecepatan dan Arah Arus}

Model kecepatan dan arah arus diolah dengan pendekatan hidrodinamika, dengan menggunakan persamaan kontinuitas dan persamaan momentum yang dirata-ratakan dengan nilai kedalaman. Data yang digunakan menggunakan data digitasi garis pantai dan data batimetri. Time interval simulasi model dan running model yang diolah pada saat pasang harian, yaitu pada 19 Agustus 2020 pukul 10.00 WIB . Data garis pantai didapatkan dari peta Rupa Bumi Indonesia dan data batimetri dari hasil pengolahan data BATNAS. Hasil yang diperoleh berupa vector plot arus di dalam petaselanjutnya hasil model diverifikasi dengan cara membandingkan hasil model dengan hasil pengukuran arus lapangan sehingga diketahui nilai error model. Verifikasi yang digunakan dalam penelitian ini menggunakan RMSE (Root Mean Square Error) Menurut Chai dan Draxler (2014), RMSE digunakan sebagai uji statistik standar untuk mengukur kinerja model dalam studi.

Keterangan:

$$
R M S E=\quad \frac{1}{n} \sum_{i=1}^{n}\left\|\frac{p-p^{\prime}}{p}\right\|
$$

$\mathrm{n} \quad=$ Jumlah data

$p \quad=$ Data lapangan

$p^{\prime} \quad=$ Data hasil pemodelan

Besar nilai error model akan memengaruhi kualitas model. Apabila nilai RMSE kurang dari 1, maka nilai hasil pemodelan arus memiliki nilai yang baik dan dapat digunakan untuk mewakili sebagai hasil penelitian.

\section{Analisis Jenis Ukuran Butir}

Jenis ukuran butir sedimen dianalisa dengan pengayakan dan pemipetan, kemudian hasil yang didapatkan disesuaikan ke dalam segitiga penamaan sedimen - segitiga Shepard (Fadhel et al., 2017).

\section{Analisis Data KOT}

Analisa kandungan KOT dilakukan dengan metode AOAC (Association of Official Agriculture Chemist) (2002), sebagai berikut :

$$
B O=\frac{B 1-(B 2-B 3)}{B 1} \times 100 \%
$$

dimanaBO $=$ Bahan organik sedimen kering $(\%)$

B1 = Berat awal sedimen kering (gram)

B2 = Berat akhir sedimen kering (gram)

B3 = Berat krus porselen (gram)

$$
\text { C-Organik }=B O \times 0,58
$$


Keterangan :

C-Organik $=$ Karbon organik $(\%)$

$\mathrm{BO}=$ Bahan organik $(\%)$

$0,58=$ Faktor konversi bahan organik ke karbon

Penentuan kriteria kandungan karbon organik total (KOT) dalam sedimen dasar berdasarkan Reynold (1971) pada Tabel 1.

Tabel 1. Kriteria KOT dalam Sedimen Dasar

\begin{tabular}{ccc}
\hline No & $\begin{array}{c}\text { Kandungan Karbon } \\
\text { Organik (\%) }\end{array}$ & Kriteria \\
\hline 1 & $>35$ & Sangat Tinggi \\
2 & $17-35$ & Tinggi \\
3 & $7-17$ & Sedang \\
4 & $3,5-7$ & Rendah \\
5 & $<3,5$ & Sangat Rendah \\
\hline
\end{tabular}

\section{HASIL DAN PEMBAHASAN}

\section{Kualitas Perairan}

Kualitas perairan diukur secara insitu yang diukur pada kedalaman 0,8d disetiap stasiun penelitian. Parameter yang diukur berupa suhu, kecerahan, DO (Dissolved Oxygent), dan salinitas. Produktivitas perairan dapat dideksripsikan dengan mengukur kualitas perairan tersebut. Hasil pengukuran dapat lihat pada Tabel 2.

Tabel 2. Hasil Pengukuran Kualitas Perairan

\begin{tabular}{|c|c|c|c|c|}
\hline Stasiun & Suhu & Kecerahan & $\mathrm{DO}$ & Salinitas \\
\hline 1 & 30,10 & 45 & 6,70 & 31 \\
\hline 2 & 29,90 & 45 & 6,65 & 31 \\
\hline 3 & 29,60 & 50 & 6,68 & 30 \\
\hline 4 & 30,20 & 65 & 6,04 & 31 \\
\hline 5 & 29,80 & 60 & 6,89 & 31 \\
\hline 6 & 30,10 & 50 & 6,86 & 31 \\
\hline 7 & 30,30 & 45 & 6,84 & 31 \\
\hline 8 & 29,90 & 70 & 6,60 & 32 \\
\hline 9 & 29,90 & 65 & 6,95 & 32 \\
\hline 10 & 30,30 & 40 & 6,25 & 29 \\
\hline \multirow[t]{2}{*}{11} & 29,80 & 45 & 6,00 & 28 \\
\hline & $28-32 * *)$ & $>500 * *)$ & $>5 * *)$ & $33-34 * *)$ \\
\hline
\end{tabular}

\section{Kecepatan dan Arah Arus}

Kisaran vector arus model adalah $0,002-0,045 \mathrm{~m} / \mathrm{s}$ dengan arah arus dominan mengarah ke barat. Peta sebaran pola arus permukaan dapat dilihat pada Gambar 2. 


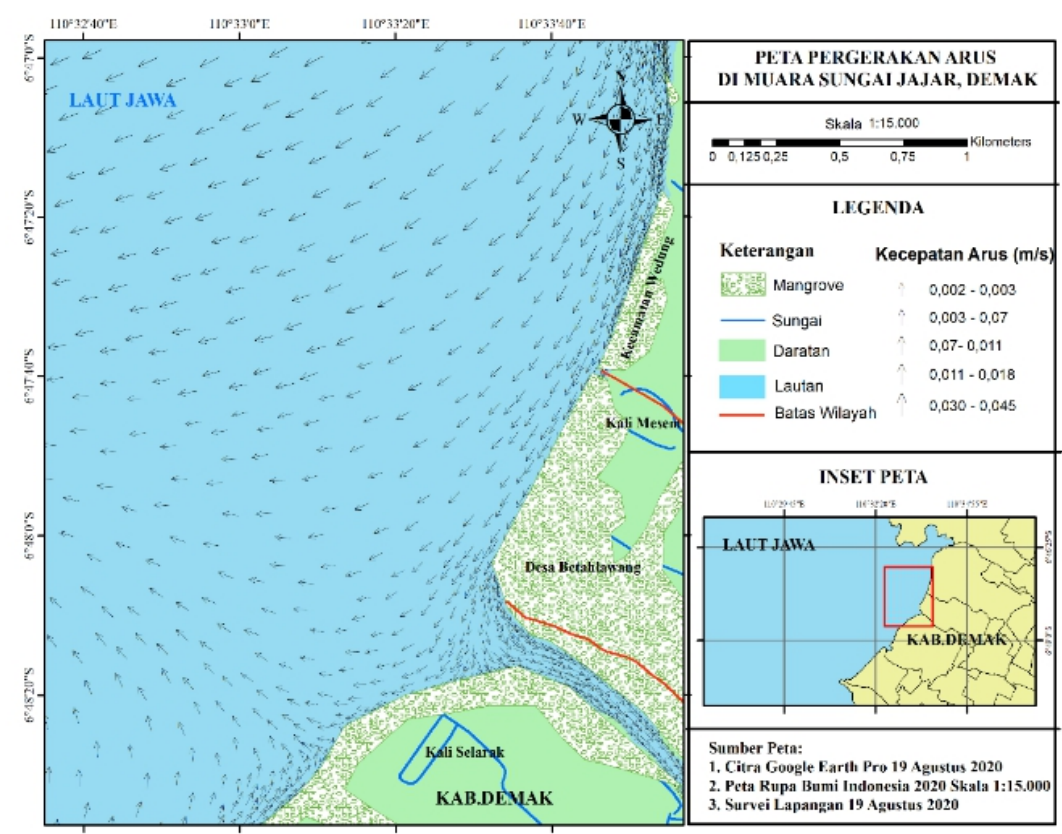

Gambar 2. Peta Pola Pergerakan Arus pada Saat Pasang Surut di Muara Sungai Jajar, Demak

Nilai verifikasi pemodelan matematik arus terhadap arus lapangan menunjukkan nilai yang baik. Pada arah U nilai RMSE menunjukkan nilai 0,3384 sedangkan pada arah V nilai RMSE Rerata menunjukkan nilai 0,2124. Kriteria hasil pemodelan tersebut tergolong baik karena berada pada kisaran nilai 0-1.

\section{Ukuran dan Jenis Sedimen Dasar}

Ukuran dan Jenis sedimen dasar pada setiap stasiun ditunjukkan dalam peta sebaran sedimen dasar (Gambar 3). Sedimen pasir tersebar di perairan dangkal yaitu pada kedalaman $0-1 \mathrm{~m}$ dan dominan berada didaerah utara Muara Sungai Jajar dan sedimen lanau tersebar di dalam sungai dan di perairan dalam pada kedalaman $>1 \mathrm{~m}$ dan dominan berada di daearah barat dan timur Muara Sungai Jajar.

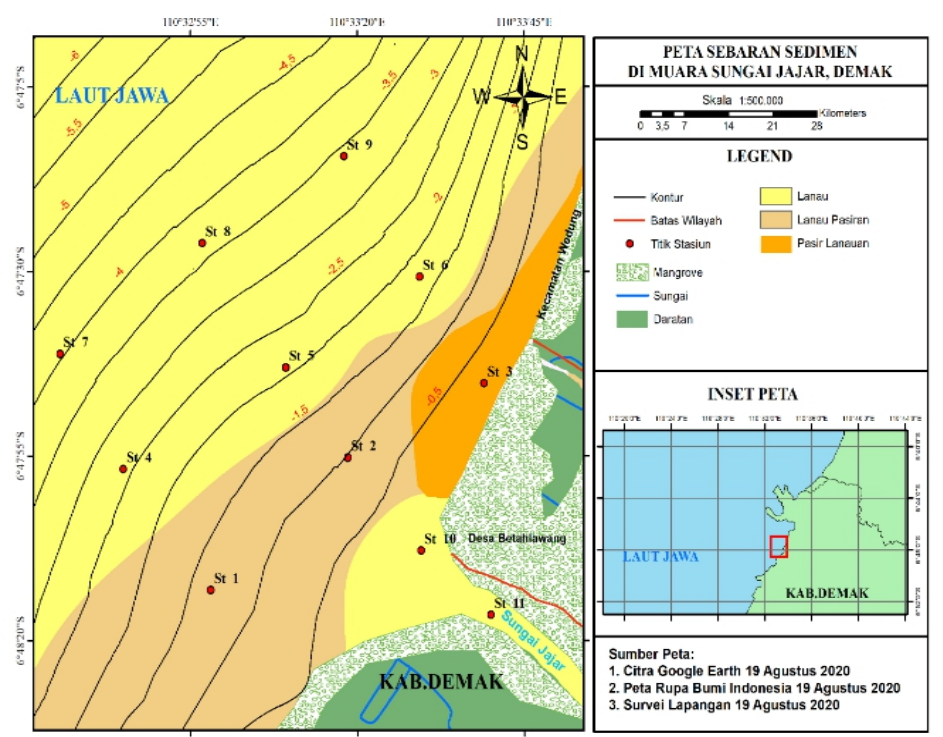

Gambar 3. Sebaran Sedimen Dasar di Muara Sungai Jajar, Demak 


\section{Karbon Organik Total}

Kandungan KOT pada sedimen dasar Muara Sungai Jajar, memiliki kisaran nilai 6,20\% sampai 8,88\%, dengan rentang $p H$ sedimen antara 4 - 5,5. Konsentrasi tertinggi terdapat pada stasiun 11 dan yang terendah berada pada stasiun 3. Konsentrasi Karbon Organik Total (KOT) terhadap stasiun pengambilan sampel dapat dilihat pada Tabel 3. Sebaran KOT pada sedimen dapat dilihat pada Gambar 4.

Tabel 3. Tabel Konsentrasi Karbon Organik Total dan $p H$ Sedimen di Muara Sungai Jajar, Demak 19 Agustus 2020

\begin{tabular}{ccc}
\hline Stasiun & Konsentrasi KOT $(\%)$ & $\boldsymbol{p H}$ Sedimen \\
\hline 1 & 8,60 & 4,5 \\
2 & 6,67 & 5 \\
3 & 6,20 & 5,5 \\
4 & 7,79 & 5 \\
5 & 8,01 & 4,5 \\
6 & 8,17 & 4,5 \\
7 & 8,58 & 4 \\
8 & 7,54 & 4,5 \\
9 & 8,41 & 4,5 \\
10 & 8,61 & 4 \\
11 & 8,88 & 4 \\
\hline
\end{tabular}

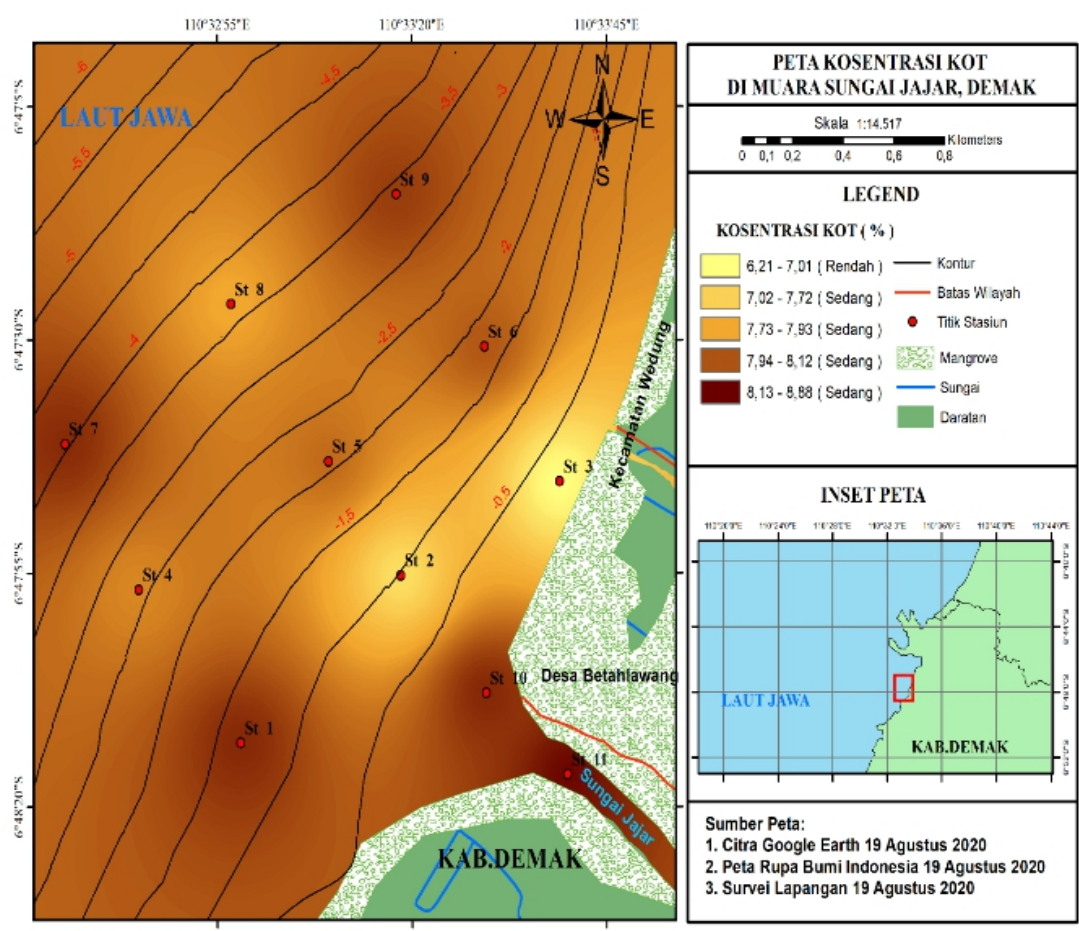

Gambar 4. Sebaran Karbon Organik Total di Sedimen Dasar Sungai Jajar, Demak

Nilai kosentrasi KOT pada sedimen diiringi dengan nilai $\mathrm{pH}$ yang berbanding terbalik (Meynita et al., 2016). Nilai pH pada sedimen dalam penelitian berkisar 4-5,5 derajat keasaman. Nilai pH yang kecil atau asam terjadi karena adanya dekomposisi bahan organik yang banyak membentuk asam-asam organik yang mengakibatkan $p H$ tanah menurun (Sari et al., 2016). Hasil analisa regresi 
bernilai 0,7908 yang berarti bernilai baik. Nilai kandungan KOT dan $\mathrm{pH}$ sedimen dapat dilihat pada table 3 dan kolerasi KOT dengan pH sedimen pada Gambar 5.

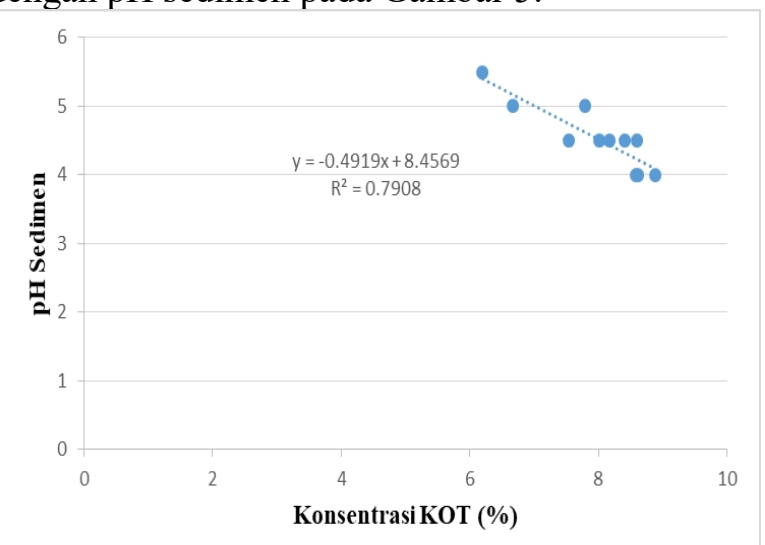

Gambar 5. Grafik Korelasi antara Karbon Organik Total (KOT) (\%) terhadap $p H$ Sedimen di Muara Sungai Jajar, Demak

Sebaran Karbon Organik terdiri dari konsentrasi sedang dan rendah. Kosentrasi KOT sedang tersebar di perairan dangkal yang sedimen berfraksi pasir, sedangkan kosentrasi KOT rendah tersebar di sungai dan tersebut berfraksi lanau. Kosentrasi KOT pada daerah Muara Sungai Jajar berada di 6,20 $-8,88 \%$. Sedimen yang bersifat lanau berada di stasiun 4,5,6,7,8,9,10,11 dengan kosentrasi KOT ratarata $8,24 \%$. Sedimen yang bersifat Pasir Lanauan berada di stasiun 1 dan 2 , dimana memiliki kosentrasi KOT rata-rata 7,63\% .Sedimen yang bersifat pasir berada pada stasiun 3 yang memiliki kosntrasi KOT 6,20\%.

Terikatnya Karbon Organik Total (KOT) pada sedimen dasar dipengaruhi oleh ukuran butir sedimen. Hasil penelitian menunjukkan sebaran sedimen berjenis lumpur kasar pada daerah muara sungai hingga laut lepas sedangkan pasir sangat halus dan pasir halus berada di pinggir pantai. Hal ini sesusai dengan pernyataan Arisa et al. (2014) yang menyatakan bahwa partikel sedimen yang berukuran kecil memiliki kemampuan untuk mengikat bahan organik yang lebih kecil, sedangkan partikel sedimen yang berukuran lebih besar akan sulit untuk mengikat bahan organik. Korelasi antara ukuran butir sedimen dan karbon organic total dapat diliat pada Gambar 6.

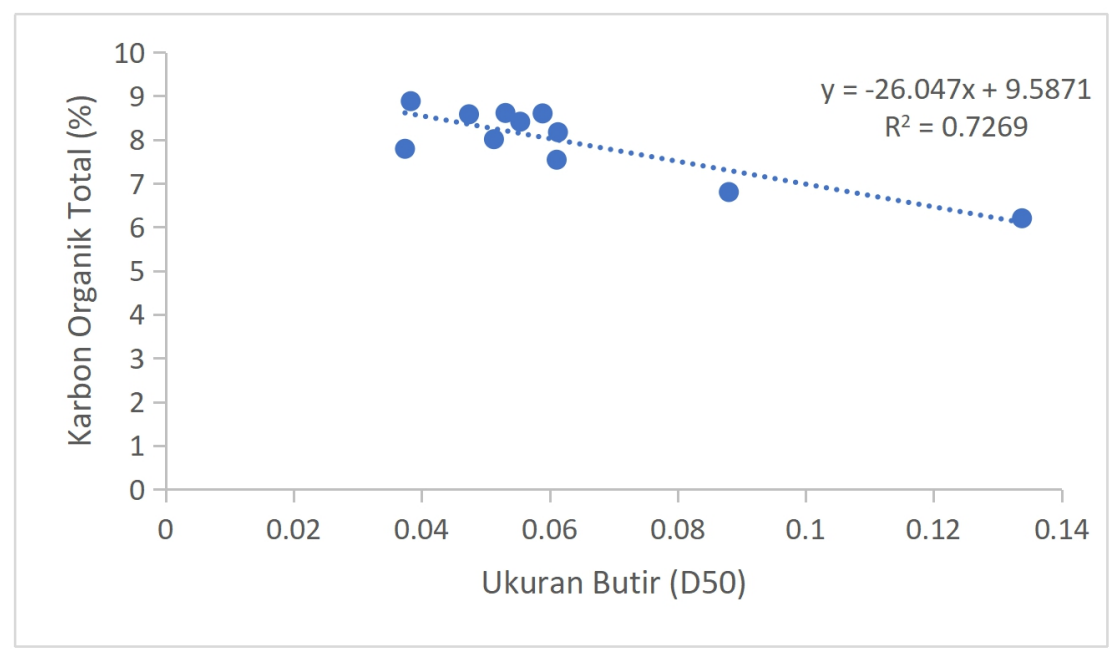

Gambar 6. Korelasi ukuran butir dengan KOT 


\section{KESIMPULAN}

Sedimen dasar di Muara Sungai Jajar berfraksi lanau, lanau pasiran, dan pasir lanauan. Sebaran sedimen $\mathrm{n}$ dipengaruhi oleh arus yang relatif kecil dimana arus berkisar 0,002 $0,045 \mathrm{~m} / \mathrm{s}$, sehingga didominasi oleh lanau karena mengalami sedimentasi. Sebaran KOT dari Muara Sungai Jajar menyebar ke arah laut terbuka, dengan kosentrasi KOT pada daerah Muara Sungai Jajar berada pada kisaran 6,20 - 8,88\%. Sedimen berukuran butir lanau dengan kosentrasi KOT berkisar 7,54 - 8,88\%, sedimen berukuran butir lanau pasiran mempunyai kosentrasi KOT antara $6,67-8,60 \%$, dan sedimen berukuran pasir lanauan mempunyai kosentrasi KOT sebesar 6,20\%. Sebaran KOT dalam sedimen dasar dipengaruhi oleh ukuran butir sedimen, semakin halus ukuran butir maka akan semakin banyak pengikatan terhadap KOT.

\section{DAFTAR PUSTAKA}

Brahmantyo, B., Miharja, D.K., Santoso, B., dan Tjasiono, B. 2013. Pengantar Ilmu dan Tekhnologi Kebumian. CV. Bumi Printing, Bandung, $337 \mathrm{hlm}$.

Chai, T. dan Draxler, R. R. 2014. Root Mean Square Error (RMSE) or Mean Absolute Error (MAE)?-Arguments Against Avoiding RMSE in The Literature. Geosci. Model Dev. 7: 1247-1250.

Dewanti, N.P., Muslim, dan Wahyu, R.P. 2016. Analisis Kandungan Karbon Organik Total (KOT) dalam Sedimen di Perairan Sluke Kabupaten Rembang. Jurnal Oseanografi. 5(2): 202-210.

Effendi, H. 2003. Telaah Kualitas Air Laut Bagi Pengelolaan Sumberdaya dan Lingkungan Perairan. Kanisius. Yogyakarya. $249 \mathrm{hlm}$.

Nagur, Y.K. 2017. Kajian Hubungan Bahan Organik Tanah Terhadap Produktivitas Lahan Tanaman Padi di Desa Kebonagung. Fakultas Pertanian Universitas Pembangunan Nasional "Veteran". Yogyakarta. $72 \mathrm{hlm}$.

Pranowo, W.S., Adi, N.S., Rustam, A., Kepel, T.L., Subki, B.A., Adi, T.R., Wirasantosa, S. 2010. Rencana Strategis Riset Karbon Laut di Indonesia, Edisi II-Tahun 2010. Badan Penelitian dan Pengembangan Kelautan dan Perikanan. Jakarta. $77 \mathrm{hlm}$.

Prasetyawan, I.B., Maslukah, L., dan Rifai, A. 2017. Pengukuran Sistem Karbon Dioksida $\left(\mathrm{CO}_{2}\right)$ sebagai Data Dasar Penentuan Fluks Karbon di Perairan Jepara. Buletin Oseanografi Marina. 6(1): 9-16.

Prihatin, M.S., Suprapto, D., dan Rudiyanti, S. 2016. Hubungan Nitrat dan Fosfat dengan Klorofil-a di Muara Sungai Jajar Kabupaten Demak. Diponegoro Journal of Maquares. 5(2): 27-34.

Reynold, S.G. 1971. A Manual of Introductory Soil Science and Sample Soil Analysis Methods. South Pacific Commission, New Caledonia. 223 p

Sari, N.M., Sudarsono., Darmawan. 2017. Pengaruh Bahan Organik terhadap Ketersediaan Fosfor pada Tanah-Tanah Kaya Al dan Fe. Buletin Tanah dan Lahan. 1(1): 65-71.

Syauqiah, I., Mayang, A., Hetty, A.K. 2011. Analisis Variasi Waktu dan Kecepatan Pengaduk pada Proses Adsorpsi Limbah Logam Berat dengan Arang Aktif. Info Teknik. 12(1): 1120 .

Sihombing, D.Y.S, Zainuri, M., Maslukah, L, Widada, S dan Atmodjo, W. Studi Sebaran Ukuran Butir Sedimen di Muara Sungai Jajar, Demak Jawa Tengah. Indonesian Journal of Oceanography, 3(1) : 1-9

Wijayanto, A., Purnomo, P.W., Suryanti. 2015. Analisis Kesuburan Perairan Berdasarkan Bahan Organik Total, Nitrat, Fosfat Dan Klorofil-A Di Sungai Jajar Kabupaten Demak . Diponegoro Journal Of Maquares 4( 3) : 76-83 